\title{
The Efficiency of a Simple Stabilization Structure in a Water Reservoir
}

\author{
Petr Pelikán ${ }^{1 *}$, Miloslav Šlezingr ${ }^{1}$, Jana Marková1, Lenka Gernešová1, \\ Jana Rosíková ${ }^{1}$, Stanislav Carbol ${ }^{1}$, Kristýna Vejtasová ${ }^{2}$ \\ 'Faculty of Forestry and Wood Technology, Mendel University in Brno, \\ Zemědělská 3, 61300 Brno, Czech Republic \\ ${ }^{2}$ Faculty of Regional Development and International Studies, Mendel University in Brno, \\ třída Generála Píky 2005/7, 61300 Brno, Czech Republic
}

Received: 22 May 2017

Accepted: 23 July 2017

\begin{abstract}
The Osada Recreation Area on the left bank of Brno Valley Dam (Czech Republic) represents a location that is extremely affected by the abrasion process due to a combination of adverse factors (fetch related to the dominant wind speed and direction over the water surface causing wave motion, the geological structure and morphology of banks, boat traffic). Our research focused on confirming the hypothesis that properly designed low-cost biotechnical structures can contribute to the active stabilization of a bank under special protection status. The hypothesis was verified by the method of wave train analysis (to prove wave height reduction) and spectral analysis (to prove wave energy dissipation due to breaking) of synchronized data collection of wave motion. The records of water surface motion were taken with the aid of electronic devices on the windward and leeward sides of the structure specifically assembled for the purposes of our research. Comparing the results of both sensors proved the effect of the stabilizing structure (double willow wattling) consisting in wave height and peak spectral energy density reduction. The leeward values decreased to approximately half the windward values due to the process of waves passing through the structure and energy dissipation.
\end{abstract}

Keywords: characteristic wave height, engineering design, water wave mechanics, wave period, wave spectra

\section{Introduction}

Brno Valley Dam on the Svratka River $(56.19 \mathrm{~km})$ was put into operation in 1940 to decrease the damage caused by river flow during floods, to supply water to the city of Brno, and to control the flow under the dam. The area of the water reservoir is 259 ha with a total volume of 17.7 million $\mathrm{m}^{3}$.

The banks of the reservoir in the Osada area are continuously damaged to an approximate length of 250 $\mathrm{m}$, where the slope-to-vertical abrasion caverns reach heights of up to $5 \mathrm{~m}$ (detailed localization GPS: the banks from $49^{\circ} 14^{\prime} 44.063^{\prime} \mathrm{N}, 16^{\circ} 30^{\prime} 22.781^{\prime \prime} \mathrm{E}$ to $49^{\circ} 14^{\prime} 45.298^{\prime}$ 'N, $\left.16^{\circ} 30^{\prime} 11.502 ’ \mathrm{E}\right)$.

*e-mail: petr.pelikan@mendelu.cz 
We can observe one of the negative effects of abrasion, namely shoreline retreat, which endangers the adjacent buildings and other structures (e.g., recreational facilities) and even visitors to the reservoir [1]. In Osada, the situation has reached a state where abrasion caverns, caused primarily by human activities (construction and operation of the reservoir), represent kingfisher habitat (Alcedo atthis, L.). As a result, there is a conflict of interests as the banks are subject to special protection status, under which the banks are not allowed to be altered and traditional (passive) stabilization methods are forbidden.

A measure that could contribute to the solution of the problem is the application of active stabilization structures that would act as partially or fully submerged offshore breakwaters. Hence the structures would mitigate scouring of the banks by wave motion and may slow the abrasion process.

The main objectives of research can be specified as follows:

1) Verifying the hypothesis that low-cost biotechnical structures are able to reduce the energy of wave motion representing the most important factor in the abrasion process.

2) Determining the efficiency of the structures based on statistical methods and hindcasting.

The results are related to the evaluation of data observed around one stabilization structure - double willow wattling - due to the rational extent of the article.

\section{Material and Methods}

\section{Design of Experiment}

Our research investigated different offshore structures, namely simple and double willow wattling, a wooden palisade, and a gabion wall. The structure locations were consulted with Povodí Moravy, administrator of the Brno Water Reservoir. The area was geodetically surveyed in detail with staking of altitudinal points for purposes of construction (total station, geodetic GPS with RTK correction).

The general principle of wave motion mitigation consists of the process of wave breaking when the windward waves reach the structure (Fig. 1). Since the structure of willow wattling is designed to be permeable, not all energy of the original waves is eliminated [2]. So we can also observe waves with reduced parameters on the leeward side of the structure. The difference between windward and leeward values of wave parameters is considered to be the efficiency of the structure.

\section{Data Collection}

The data are represented by records of water surface motion at a given place and time. The records were taken with the aid of electronic devices especially assembled for the purposes of our research. The apparatus is composed of a fluid level sensor based on electric resistance, a device controller with datalogger (Arduino Technology), and a power supply (DC 9V in a series of monocells). The sensor output is the value of electric resistance in ohms dependent on the proportion of sensor submersion. Calibration was accomplished using the statistical method of nonlinear regression - Gauss-Newton algorithm (nonlinear least squares) in QCExpert 3.3 software. The resulting model was incorporated into the program written in programming language similar to $\mathrm{C}++$ code. The error of the device can vary from 5 to $10 \mathrm{~mm}$ (individual sensors slightly differ from each other) and the logging interval was set at up to 13 records per second (maximum possible value due to the limited performance of device controller). The data are logged on an SD card in text format and all the components are mounted on the mobile telescopic tripod.

Data collection (detailed course of water surface motion) was accomplished with the aid of synchronized sensors anchored to the bottom windward and leeward sides of the structure.

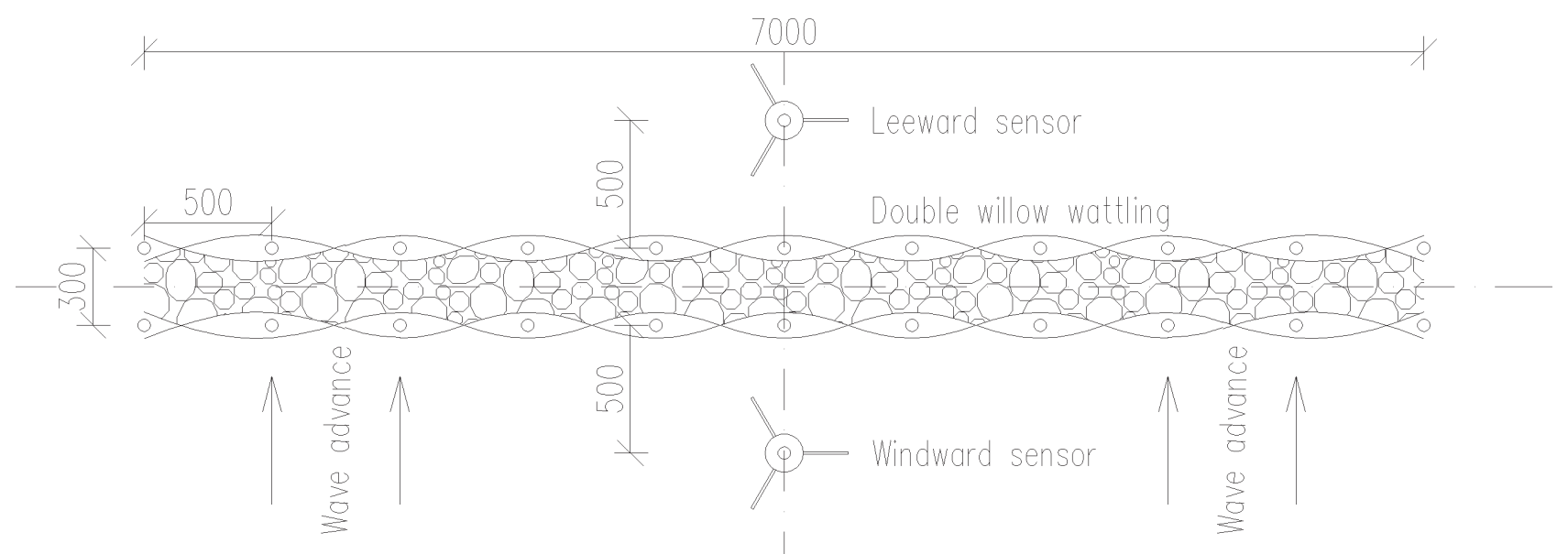

Fig. 1. Plan view of the experimental structure and measurement set up. 


\section{Statistical Data Processing}

Hindcast means a statistical calculation determining probable past conditions of water surface at a given place and time. The simplest method describing water surface is called the first-order theory (linear waves) - the original regular wave theory developed by Airy (1845). The higher order theories were developed [3] and they have been frequently used for modelling waves along sea coastlines [4-5]. Conversely, an irregular wave train is constructed by linear superposition of a number of linear wave components [6-7]. Wave train analysis is based on statistical processing of observed data represented by the record of water table motion in a given point [8-9]. Two of the most important parameters related to the irregular wave theory are wave height $H$ and wave period $T$ with their characteristic values compliant with the valid Czech National Standard CSN 75 0255: "Calculation of wave effects on hydrotechnical structures on water reservoirs" [10].

The performed statistical analyses also involved exploratory data analyses for determining basic and ordinal descriptive statistics and Box-Cox transformations for the estimation of still water level (SWL) for individual wave records (datasets). The analyses were performed using Statistica 12 and QCExpert 3.3 software [11]. The final efficiency of each structure was evaluated pursuant to a comparison of the windward and leeward values of wave heights and peak spectral energy densities.

\section{Results and Discussion}

\section{Construction of Experimental Structure}

Low-cost offshore technical and biotechnical solutions on the principle of partially or totally submerged breakwaters were preferred. The following results are related to the double willow wattling realized in experimental sites along the reservoir shoreline in spring, when the water level in Brno Reservoir is usually operated at $4 \mathrm{~m}$ below its standard conditions.

In general, there are two essential requirements coherent to the structure dimensions. The first one is sufficient depth on the windward and leeward sides to provide conditions for data collection (wave observing). The second one is the proper altitudinal emplacement with respect to the most occurring water level in the reservoir.

Water level data for 2010-14 were provided by the reservoir administrator (the values of still water level in the reservoir at 07:00 archived for each day). The banks are periodically endangered by waves from April to September, when the water level is usually operated around the level of full supply capacity. The data from the five years were statistically processed and the value of 228.80 m.a.s.l. represents the most frequent water level during the season from April to September.

The structure was built on an abrasion platform $5 \mathrm{~m}$ from the toe of the abrasion cavern (height of approximately $4-5 \mathrm{~m}$ ). The dimensions of the structure

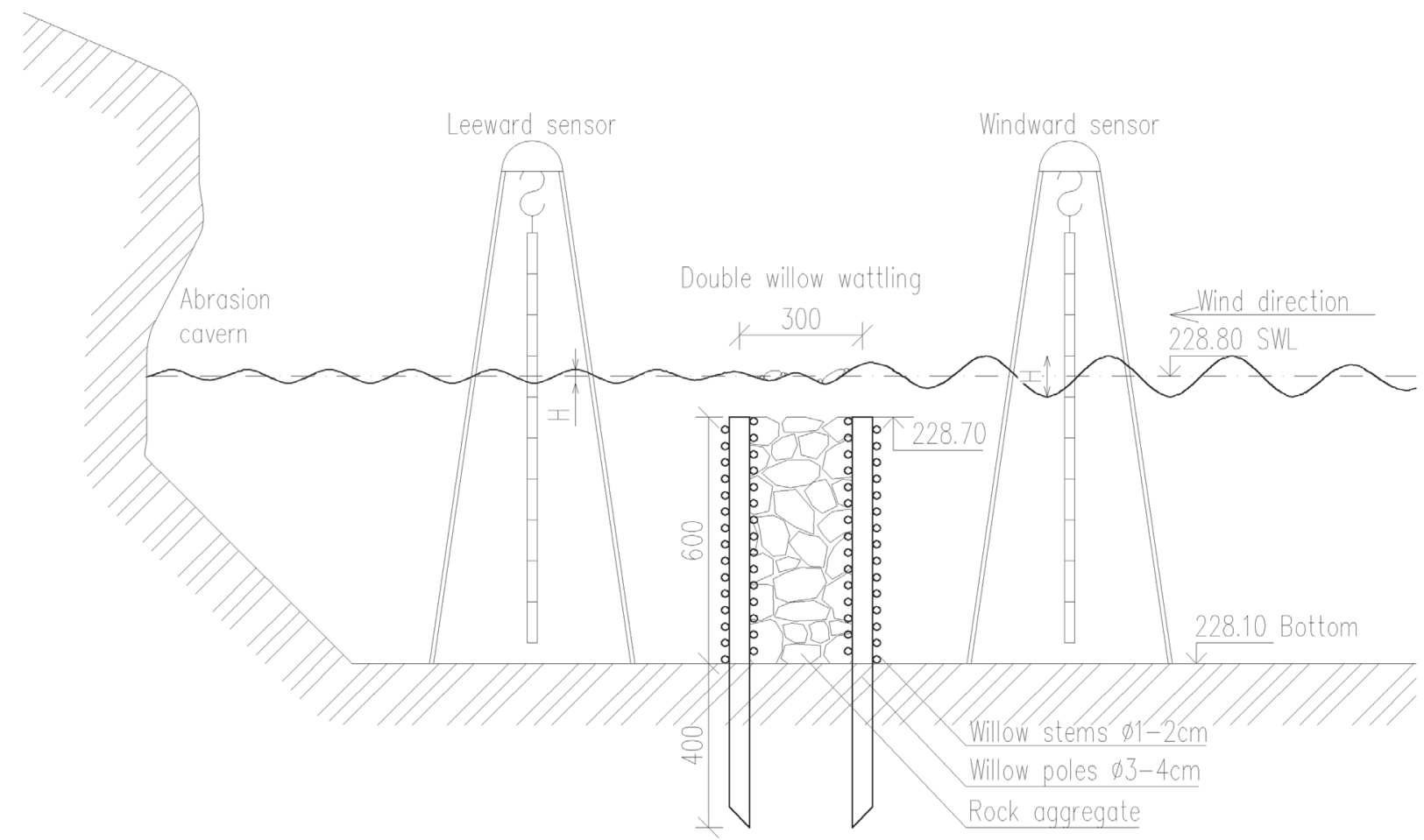

Fig. 2. Scheme of the experimental wave observation. 
are $0.6 \times 0.3 \times 7.0 \mathrm{~m}$ (height $\times$ width $\times$ length). The material for the structure is $3-4 \mathrm{~cm}$ thick willow poles 1 $\mathrm{m}$ long, 1-2 cm thick willow stems with a minimal length of $1.5 \mathrm{~m}$, and local rock aggregate (Fig. 2). The poles were rammed into the abrasion platform at a mutual distance of $0.5 \mathrm{~m}$ and interlaced by willow stems. Two rows of wattling (built in parallel $0.3 \mathrm{~m}$ apart) were filled with local rock aggregate from the abrasion platform of various sizes (consuming $0.18 \mathrm{~m}^{3}$ per meter). The final structure represents a combination of biological and technical elements. The structure is located along the shoreline. The altitudinal emplacement was adjusted with respect to the most occurring water level in the reservoir during the main season (April to September). The top of the structure lies in the elevation of 228.70 m.a.s.l. In the main season, the structure is usually submerged and the top edge is approximately $5-10 \mathrm{~cm}$ below the water surface. Hence the structure behaves as a submerged breakwater. The cost of the structure consists only in the cost of human work because all of the material used comes from local sources: willow poles and stems from adjacent stands and rock aggregate from the abrasion platform.

\section{Collecting Wave Data and Statistical Processing}

The periods and heights of irregular waves are not constant with time, changing from wave to wave. Wave-by-wave analysis determines wave properties by finding statistical quantities (i.e., heights and periods) of the individual wave components present in the wave record. It is recommended that the wave records must be of sufficient length to contain several hundred waves for the calculated statistics to be reliable. The next results are related to the experimental measurements of water surface motion realized during the total time of 53 minutes for each sensor in conditions of wave progress perpendicular to the windward front of the structure. Hence, all datasets contained more than 80,000 records of water surface elevation (about 13 records per second with time stamp). The entire synchronized wave records (wave trains) were divided into five-minute time segments before subsequent data processing. The synchronized records of water surface motion represent the raw data collected simultaneously on the windward and leeward sides of the structure.

Wave train analysis is essentially a manual process of identifying the heights and periods of the individual wave components, followed by a simple counting of wave crests and troughs with time stamps in the wave record [9, 12]. The process began by dissecting the entire record into a series of subsets for which individual wave heights and periods were then noted. In order to reduce the manual effort, it is customary to define wave height as the vertical distance between the lowest and the highest points, while wave period was defined as the horizontal distance between two successive wave crests (similar statistical values to the zero-crossing period). In this step of analysis (statistical pre-processing), all redundant points were discarded. The process was accomplished in MS Excel with the aid of logical decision functions, filtering, and scripts. Final wave records intended for the next statistical operations contained only the points representing local minima and maxima, whose joins consecutively cross the zero-line. Approximately 2,900 windward and 2,550 leeward waves were extracted by means of the zerocrossing method in total.

Subsequently, wave records were statistically processed with emphasis on the verification of the hypothesis that the investigated structure is able to reduce the values of wave parameters. Structure efficiency was investigated from two points of view: the ability to reduce wave height and the ability to reduce wave energy.

The results of wave train analyses are represented by a dataset containing values of heights and periods of individual waves from windward and leeward sensors. The datasets were suitable for the direct analysis of wave heights because we were able to determine the following values related to the specific probability of occurrence: mean wave height $H_{50 \%}$, characteristic wave height $H_{13 \%}$, and maximum wave height $H_{1 \%}$ (i.e., wave heights referring to the 50 th, $87^{\text {th }}$, and 99 th percentiles in datasets). The specific values relate to the calculations widely applied in the design and stabilization practices.

The energy of waves was graphically expressed by means of one-dimensional wave spectra JONSWAP (Fig. 3). The graphical solution shows the dependence between frequency $f$ and spectral energy density $E$ of particular waves in the record. The analysis also identifies the waves carrying the largest part of energy in spectra. Peak spectral energy density agrees with waves with peak period $T_{p}$. The relationship between peak period $T_{p}$ and limiting frequency for a fully developed wave $\operatorname{spectrum} f_{p}$ is: $f_{p}=1 / T_{p}$. The previously described wave train analysis and its statistical processing also provides other important information, namely mean period $T_{m}$. The values of mean period of particular wave records represent an essential input for spectral analysis. Unknown values of peak periods were computed as follows: $T_{p}=1.2 T_{m}$ (which was verified during the JONSWAP project [13]).

The wave spectra of each wave record (time segment) was worked out by sequential computation of the discrete value of spectral energy density for waves in the record by means of the following second generation five-parameter model of JONSWAP.

$$
E(f)=\frac{\alpha^{\prime} g^{2}}{2 \pi^{4} f^{5}} \exp \left[-1.25\left(\frac{f}{f_{p}}\right)^{-4} \gamma^{\exp \left[-\frac{\left(\frac{f}{f_{p}}-1\right)^{2}}{2 \sigma^{2}}\right]}\right.
$$

The empirical parameters $\alpha^{\prime}, \gamma$, and $\sigma$ were used in default values corresponding to the results of the JONSWAP project $[9,13]$. When the discrete values are joined, the curve represents the final shape of wave spectra. The area under the curve represents the absolute value of energy carried by waves in spectra, but these extensional computations will be the subject of further research. 
Table 1. Results of wave train and spectral analysis.

\begin{tabular}{|c|c|c|c|c|c|c|}
\hline Time segment & Sensor & $\mathbf{H}_{50 \%}$ & $\mathbf{H}_{13 \%}$ & $\mathbf{H}_{1 \%}$ & $\mathbf{T}_{\mathrm{p}}$ & $\mathbf{E}(\mathbf{f})$ \\
\hline (s) & No. & (m) & (m) & (m) & (s) & $\left(\mathrm{cm}^{2} \cdot \mathrm{Hz}^{-1}\right)$ \\
\hline \multirow{2}{*}{ 0-300 } & I. & 0.041 & 0.065 & 0.085 & 1.24 & 13.86 \\
\hline & II. & 0.021 & 0.028 & 0.035 & 1.02 & 5.22 \\
\hline \multirow{2}{*}{$300-600$} & I. & 0.039 & 0.062 & 0.085 & 1.25 & 14.43 \\
\hline & II. & 0.021 & 0.028 & 0.035 & 0.97 & 4.06 \\
\hline \multirow{2}{*}{$600-900$} & I. & 0.044 & 0.067 & 0.091 & 1.35 & 21.20 \\
\hline & II. & 0.021 & 0.028 & 0.035 & 0.96 & 3.86 \\
\hline \multirow{2}{*}{$900-1,200$} & I. & 0.040 & 0.063 & 0.087 & 1.21 & 12.27 \\
\hline & II. & 0.021 & 0.028 & 0.035 & 1.04 & 5.75 \\
\hline \multirow{2}{*}{$1,200-1,500$} & I. & 0.043 & 0.068 & 0.139 & 1.35 & 21.20 \\
\hline & II. & 0.014 & 0.028 & 0.035 & 0.96 & 3.86 \\
\hline \multirow{2}{*}{$1,500-1,800$} & I. & 0.041 & 0.056 & 0.079 & 1.30 & 17.56 \\
\hline & II. & 0.014 & 0.028 & 0.034 & 1.06 & 6.33 \\
\hline \multirow{2}{*}{$1,800-2,100$} & I. & 0.035 & 0.055 & 0.070 & 1.27 & 15.62 \\
\hline & II. & 0.014 & 0.028 & 0.035 & 1.15 & 9.51 \\
\hline \multirow{2}{*}{$2,100-2,400$} & I. & 0.033 & 0.053 & 0.071 & 1.29 & 16.89 \\
\hline & II. & 0.014 & 0.028 & 0.041 & 1.25 & 14.43 \\
\hline \multirow{2}{*}{$2,400-2,700$} & I. & 0.032 & 0.047 & 0.062 & 1.19 & 11.28 \\
\hline & II. & 0.014 & 0.021 & 0.034 & 1.08 & 6.95 \\
\hline \multirow{2}{*}{$2,700-3,000$} & I. & 0.037 & 0.056 & 0.082 & 1.26 & 15.02 \\
\hline & II. & 0.014 & 0.027 & 0.034 & 1.15 & 9.51 \\
\hline \multirow{2}{*}{$3,000-3,200$} & I. & 0.033 & 0.051 & 0.084 & 1.19 & 11.28 \\
\hline & II. & 0.014 & 0.027 & 0.034 & 1.23 & 13.31 \\
\hline \multicolumn{2}{|c|}{ Average efficiency } & $58 \%$ & $54 \%$ & $57 \%$ & - & $49 \%$ \\
\hline
\end{tabular}

Detailed results of the wave train and spectral analyses are presented in Table 1. The values are related to the individual time segments with an interval of five minutes (data featured in seconds) for each sensor separately (I. - data from the sensor on the windward side and II. - data from the sensor on the leeward side). A comparison of the values of both sensors within the same time segment shows the effect of the stabilizing structure consisting in wave height and peak spectral energy density reduction. The modification of wave dimensions due to the passage through the structure is apparent from columns related to the mean $\left(H_{50 \%}\right)$, characteristic $\left(H_{13 \%}\right)$, and maximum $\left(H_{1 \%}\right)$ wave heights. The next column contains the values of peak period of spectra $T_{p}$ derived from mean period $T_{m}$. The final column represents the values of peak spectral energy density $E(f)$ corresponding to computed peak frequency $f_{p}$ (demonstrating the modification of peak spectral energy on the windward and leeward sides of the structure). More illustrative graphical results of spectral analysis are depicted in Fig. 3.
The final efficiency of the structures in the reduction of wave height $\left(H_{50 \%}, H_{13 \%}, H_{1 \%}\right)$ and peak spectral energy density $E(f)$ was calculated from the relative form of values. The effect of structure (i.e., reduction) as a percentage is given as follows: [1-(leeward/ windward values)] 100 . The resulting values represent average efficiency computed from the results referring to particular time segments.

Double willow wattling manifested very good results as regards wave reduction. Although the top of the structure was approximately $5 \mathrm{~cm}$ under the current still water level during the experiment, it acted as a submerged breakwater. The structure decreased the characteristic wave height by $54 \%$ and peak spectral energy density on the leeward side reached only about half of the windward values in all.

There is quite a large peak energy reduction shown in the time period 0 to $1,800 \mathrm{~s}$ ( $69 \%$ on average) while considerably less in the time period 1,800 to $3,200 \mathrm{~s}$ ( $26 \%$ on average). The reduction variance is caused 
by the different wind conditions occurred during the experimental measurement. Generally we assume the stable wind speed and direction in the given time period for the purposes of clearly defined input values into the subsequent computations, although there are some fluctuations in reality. The investigation of a relationship between wind speed and direction, fetch, and wave heights was not the objective of this part of our research. However, we can state that the time period 0 to $1,800 \mathrm{~s}$ is characterized by the advance of the higher waves (resulting from higher wind speed). Then the relative water depth in the point of wave breaking above the top of the structure is smaller (if comparing wave height and the absolute superelevation of still water level in the reservoir as shown in Fig. 2). Thus the efficiency of the structure is higher under the mentioned conditions in contrast to the time period 1,800 to $3,200 \mathrm{~s}$. In that period the trains of lower waves were observed, for which the difference in altitude between the top edge of the structure and SWL represents relatively deeper conditions as the waves are less affected by the structure and reduction is even negligible in the final period of the measurement.

The device for recording the water level has factual technical limits relating to sensor accuracy and performance of the device controller with the datalogger. Thus, the differences between windward and leeward wave heights could be small enough to be considered a device error. The problem was eliminated by performing the measurements during the sufficient wind conditions ensuring measurable waves. There will always be some uncertainties in capturing supposed wave crests and troughs. The question arises whether approximately 13 records per second are sufficient.

Research proved that it is possible to mitigate wave motion using simple biotechnical active stabilization measures. The results indicate that better efficiency
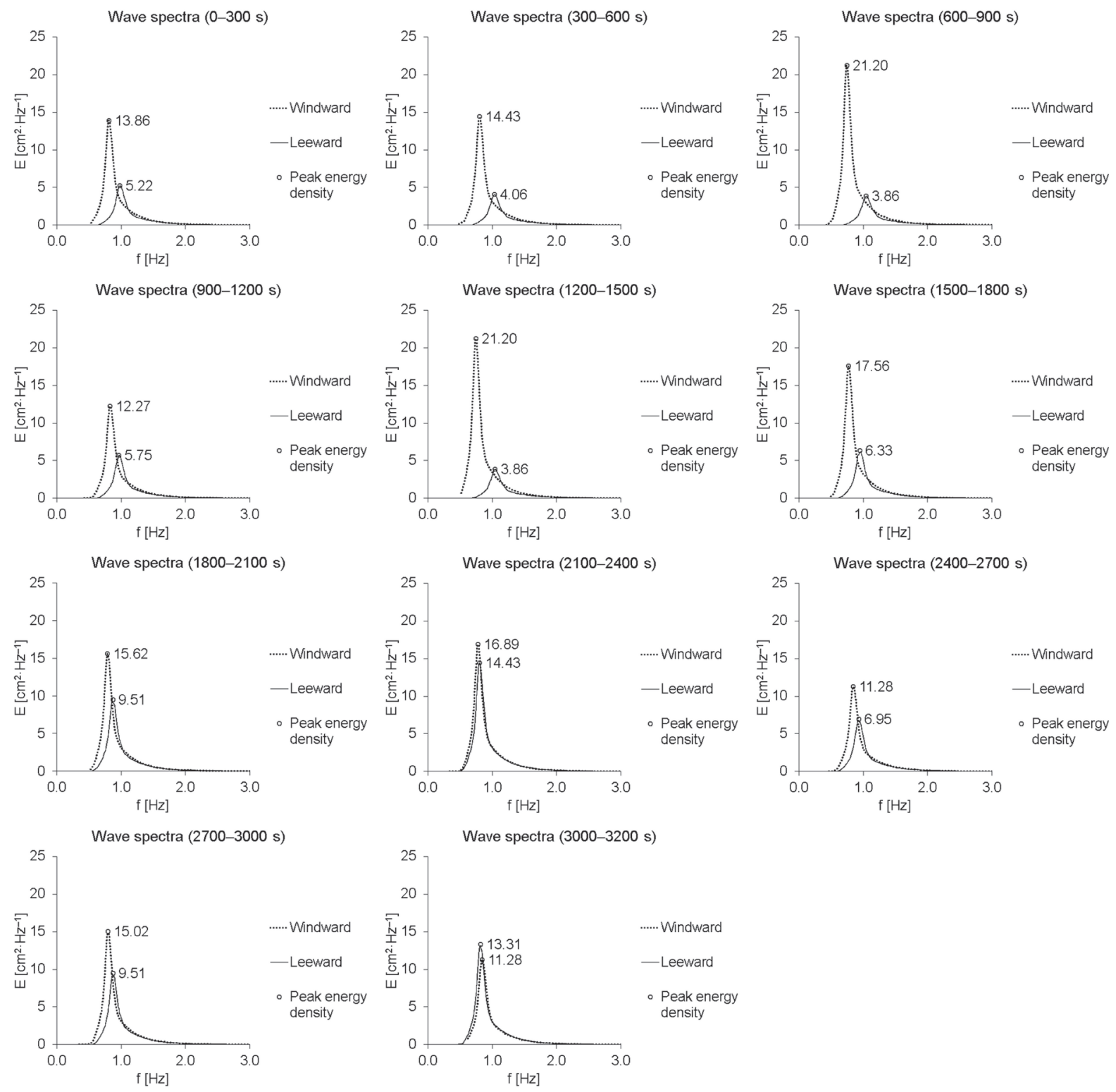

Fig. 3. Graphical results of the spectral analysis. 
could be expected from thicker structures in the direction of wave propagation. Fill rock aggregate inside structures represents the environment in which passing waves break and the energy dissipates well. The advantage of the investigated structure is its low cost and simple construction. The disadvantage of biological and biotechnical measures is the delay of their full stabilization effect until the proper rooting of vegetative components. Moreover, the structure is not very resistant during this critical period and it is prone to destruction by various disturbing natural or anthropogenic events. The construction of the investigated structures is not appropriate everywhere. The measures are especially unsuitable at the points of direct access to water in recreational areas.

The similar problem of flow and scour phenomenon around spur dikes has been investigated and solved by means of experimental and numerical methods by Karami [14]. Since the double willow wattling was designed as permeable, not all energy of windward waves were reduced; however, the fill aggregate inside structures is an environment in which passing waves break and the energy dissipates well. The siltation of reservoirs represents a serious problem with impacts on the accumulation volume and water quality in the reservoir, and the river/sediment transport mechanism has been investigated by, e.g., Wang [15]. The scouring of the banks by waving (abrasion) also contributes to the interior sedimentation of the reservoir [16]. Uhmannová and Smelík analyzed the material characteristics of the bottom and banks of rivers and reservoirs using methods of grain size percentile [17]. The experimental structure of double willow wattling is intended to consecutively accumulate fine-grained material from the deteriorated bank on its leeward side and thus prevent further siltation of the reservoir. Changes in the retention of reservoirs due to the accumulation of sediments were investigated by Kubinský and Fuska using modern bathymetric surveying technologies [18], and the predicting the siltation process was verified by Junáková [19]. Great potential lies in GIS modelling in the field of water management [20].

The bank abrasion and shoreline retreat are longterm processes usually caused by many factors and their adverse combinations. Our research answered the question whether the structures can mitigate wave motion and how they can modify wave shape and energy. However, today we are not able to quantify their overall effect on the dynamics of the process of abrasion and its slowdown in particular locations. This could be the subject of further long-term investigation.

\section{Conclusions}

The project in general relates to the construction and operation of water reservoirs, their impact on the immediate environment, and integration into the landscape. Selecting experimental sites in Brno valley dam builds on research activities of leading Czechoslovak experts on the effects of waves on structures and riparian areas, including research into stabilization measures and prevention of bank abrasion.

The main benefit of the project is the investigation of low-cost biotechnical active shore protection structures representing little explored stabilization measures. Active stabilization measures can contribute to shoreline protection in locations in special conflict of interests where traditional passive stabilization is not allowed. The reduction of the proceeding wave energy by offshore structures may mitigate the effects of scouring at the point of interaction between water level and the bank. The gain also consists of research of wave motion and its parameters on water reservoirs in the Czech Republic, which is currently found out of interest (in contrast to the recent past), and the continuity of research with added value, consisting of the implementation of state-of-theart scientific knowledge and methods. Generally, the estimation of wave parameters in a water reservoir is an essential task in the design of stabilization measures, both active and passive with proper design of structure dimensions and altitudinal adjustment.

Part of the research project focused especially on active stabilization measures (double willow wattling) and involved several activities to meet the set objectives. Workflow included the design of experiment (geodetic survey and design and construction of experimental structures), development of device for recording the water surface motion, data collection and data processing wave train analysis (to prove wave height reduction), and spectral analysis (to prove wave energy dissipation due to breaking). The results of the complex interdisciplinary research project proved that wave height and energy decreased to approximately half the value due to the effect of the structure.

The hypothesis that low-cost technical and biotechnical structures are able to decrease the energy of wave motion was confirmed and the efficiency of structures was determined based on statistical methods.

\section{Acknowledgements}

Our research was funded from the following grants and projects:

- LDF_VT 2015011 "Active anti-abrasion structures," Internal Grant Agency, Mendel University in Brno

- LDF_PSV_2016002 "Minimizing losses of forest and agricultural land due to erosion and abrasion processes in the landscape," Internal Grant Agency, Mendel University in Brno

The authors wish to thank Povodí Moravy, s.p. (the reservoir administrator) for permission to perform the research. 


\section{Units and Nomenclature}

$\alpha^{\prime}(-)$ equilibrium coefficient (intensity of spectra); $\alpha^{\prime}=0.0081$

$\gamma \quad(-)$ spectral peakedness parameter (peak enhancement factor); $\gamma=3.3$

$\sigma \quad(-)$ spectral width parameter; $f<f_{p}: \sigma=0.07 ; f>f_{p}$ : $\sigma=0.09$

$E(f) \quad\left(\mathrm{m}^{2} \cdot \mathrm{Hz}^{-1}\right)$ spectral energy density as a function of frequency

$f(\mathrm{~Hz})$ wave frequency

$f_{p}$ (Hz) frequency of the spectral peak used in the JONSWAP spectra

$g\left(\mathrm{~m} \cdot \mathrm{s}^{-2}\right)$ gravitational constant

$H$ (m) wave height

$H_{x \%}(\mathrm{~m})$ wave height exceeded by $\mathrm{x} \%$ of all wave heights

$T$ (s) wave period

$T_{m}$ (s) mean wave period

$T_{p}$ (s) peak wave period (associated with the largest wave energy)

\section{References}

1. ŠLEZINGR M. Stabilisation of reservoir banks using an "armoured earth structure". Journal of Hydrology and Hydromechanics, 55, 64, 2007.

2. BABANIN A. Breaking and dissipation of ocean surface waves. Cambridge University Press, New York, 2011.

3. CHEN G.-Y, WU C.-L., WANG Y.-H. Interface depth used in a two-layer model of nonlinear internal waves. Journal of Oceanography, 70, 329, 2014.

4. HSIEH C.-M., HWANG R.R., HSU J. R.-C., CHENG M.-H. Numerical modelling of flow evolution for an internal solitary wave propagating over a submerged ridge. Wave Motion, 55, 48, 2015.

5. JANNO J., ŠELETSKI A. Reconstruction of coefficients of higher order nonlinear wave equations by measuring solitary waves. Wave Motion, 52, 15, 2015.

6. COASTAL ENGINEERING RESEARCH CENTER. Shore protection manual. $4^{\text {th }}$ ed., U.S. Government Printing Office, Washington, D.C., 1984.

7. WORLD METEOROLOGICAL ORGANIZATION. Guide to wave analysis and forecasting. $2^{\text {nd }}$ ed., WMO No. 702, Geneva, Switzerland, 1998.

8. IAHR. List of Sea State Parameters. Intl. Assoc. Hydr. Res., Suppl. to Bull. No. 52, Brussels, 1986.
9. U.S. ARMY CORPS OF ENGINEERS. Coastal engineering manual. Engineer Manual 1110-2-1100, I-VI, Washington, D.C., 20022011.

10. UNMZ. ČSN 750255 Calculation of wave effects on hydrotechnic structures on water reservoirs. Institute for Technology Standardization, Metrology and State Testing, Praha, 1987 [In Czech].

11. MELOUN M., MILITKÝ J. Statistical analysis of experimental data. Praha: Academia, The Academy of Sciences of the Czech Republic, 2004 [In Czech].

12. PELIKÁN, P., KOUTNÝ, L. Hindcast of Wind Driven Wave Heights in Water Reservoirs. Soil and Water Research, 11 (3), 205, 2016.

13. HASSELMANN K., BARNETT T.P., BONWS E., CARLSON H., CARTWRIGHT D.C., ENKE K., EWING J., GIENAPP H., HASSELMANN D.E., KRUSEMAN P., MEERBURG A., MULLER P., OLBERS D.J., RICHTER K., SELL W., WALDEN H. Measurements of wind-wave growth and swell decay during the Joint North Sea Wave Project (JONSWAP). Deutsches Hydrographisches Institut, Hamburg, 1973.

14. KARAMI H., BASSER H., ARDESHIR A., HOSSEINI S. H. Verification of numerical study of scour around spur dikes using experimental data. Water and Environment Journal, 28, 124, 2014.

15. WANG H., ZHANG Z., SONG D., ZHOU Y. AND LIU X. Water and sediment transport mechanisms in a large riverconnected lake. Water and Environment Journal, 29, 391, 2015.

16. PELIKÁN P. The effect of shore abrasion on the transformation of the bank of water reservoirs. [Ph.D. Thesis.] Mendel University in Brno, Faculty of Forestry and Wood Technology, Brno, 2013 [In Czech].

17. UHMANNOVÁ H., SMELÍK L. Methods for determination of grain size curves. Journal of Landscape Management, $\mathbf{5}$, 56, 2014.

18. KUBINSKÝ D., WEIS K., FUSKA J., LEHOTSKÝ M., PETROVIČ F. Changes in retention characteristics of 9 historical artificial water reservoirs near Banská Štiavnica, Slovakia. Open Geosciences, 7, 880. ISSN 2391-5447, 2015.

19. JUNÁKOVÁ N., KLEŠČOVÁ Z., GERGELOVÁ M. Prediction of siltation process in reservoirs. Journal of Landscape Management, 5, 7, 2014.

20. ŠINKA K., KALETOVÁ T. Determining the characteristics of direct runoff from real rain using GIS environment. Acta Horticulturae et Regiotecturae, 16, 48, 2013. 